\title{
ДИСТАНЦИОННОЕ ОБУЧЕНИЕ, ИЛИ ПРОБЛЕМА ОБСТОЯТЕЛЬСТВ. ПОЛЕМИЧЕСКИЕ ЗАМЕТКИ НА АКТУАЛЬНУЮ ТЕМУ
}

\section{DISTANCE LEARNING, OR THE PROBLEM OF CIRCUMSTANCES. POLEMICAL NOTES ON THE CURRENT TOPIC}

\section{R. Tatatintseva}

Summary: The text of the article gives a broad view on the problems of distance learning. Confidently and prospectively modeled by the researchers in the past years, in the total practice of distance education, simultaneously and rigidly imposed by the confrontation with the coronavirus pandemic, distance learning appeared to be a new reality of the issue, which significantly adjusted its capabilities at the current stage of the corresponding technical capabilities. The new conditions the conditions of moderate optimism-allow us to talk about the applied importance of distance education in the near future, as well as about the prematurity of large-scale national distance projects at all levels of the Russian education system.

Keywords: distance learning, online, offline, distance learning platforms, corporate identity, cognitiveness, force majeure, new realities, current opportunities and prospects.
Татаринцева Регина Игоревна старший преподаватель, Финансовый университет при Правительстве Российской Федерации regina_tatarinceva@mail.ru

Аннотация: Текст статьи представляет широкий взгляд на проблемы дистанционного обучения. Уверенно и перспективно моделировавшиеся исследователями в минувшие годы, в тотальной практике дистанционного образования, одномоментно и жёстко навязанной противостоянием пандемии коронавируса, дистант предстал новыми реалиями вопроса, существенно скорректировавшими его возможности на текущем этапе соответствующих технических возможностей. Новые условия - условия умеренного оптимизма - позволяют сегодня говорить лишь о прикладном, вспомогательном значении дистанционного образования в ближайшей перспективе, как и о преждевременности масштабных национальных проектов дистанта на всех уровнях российской системы образования.

Ключевые слова: дистанционное обучение, дистанционное образование, дистант, онлайн, офлайн, дистанционные образовательные платформы, корпоративность, когнитивность, форс-мажорные обстоятельства, самоизоляция, новые реалии, текущие возможности и перспективы.
«P оссийской системе образования понадобится несколько лет для организации полноценного дистанционного обучения, считает основатель Международного Ломоносовского клуба Владимир Скрипниченко» [7]. С таким взглядом сегодня трудно не согласиться. На наш взгляд, с ним охотно согласится каждый преподаватель, работавший на самоизоляции в период пандемии коронавируса или работающий сейчас дистанционно в любом звене и на любом уровне названной системы образования. И это, как говорится, более чем осязаемая реальность.

Теоретическая проблема дистанционного образования в нашей стране не нова. Продвигаясь в умозрении исследователей параллельно с компьютеризацией Российской Федерации, она шагнула уже в своё четвёртое десятилетие. Примеров тому множество, стоит лишь обозначить тему в любой поисковой системе интернета... Библиография вопроса и его хронологические рамки поразят воображение, в том числе и многоаспектностью исследований изучаемой проблемы.

Примеров и подтверждений, действительно, множество. Ограничившись лишь немногими, можно на- звать хотя бы такие значимые публикации разных лет и десятилетий: Домрачев В.Г. Дистанционное обучение: возможности и перспективы.//Высшее образование в России. - 1994. - № 3. - С.10-12; Полат Е.С. Новые педагогические и информационные технологии в системе образования / Е.С. Полат, М.Ю. Бухаркина, М.В. Моисеева, А.Е. Петров. - М.: Академия, 2009. - 272 с.; Кошкина Е.Н., Орлова Е.Р. Дистанционное обучение: реалии и перспективы.//Вестник Международного института экономики и права. - 2011. - №2; Горева О.М. Дистанционное обучение в вузе: модели и технологии /О.М. Горева, Ј.Б. Осипова. // Современ. проблемы науки и образования. - 2014. - № 5. - URL: http://www.science-education.ru/119-14612; Тихомиров В.П. Дистанционное обучение: к виртуальным средам знаний (часть 1)/Тихомиров В.П., Солдаткин В.И., Лобачев С.Л., Ковальчук О.Г. [Электронный ресурс] // Научно-практический журнал «Открытое образование». - URL: http://www.e-joe. ru/sod/99/2_99/stl58.html И многое другое, конечно, если, не боюсь повториться, прикоснуться к вопросу через компьютерную поисковую систему... В этот же ряд необходимо добавить и Федеральный закон от 29 декабря 2012 г. №273-Ф3 «Об образовании в Российской Федерации», опубликованный в «Российской газете» - Федеральный выпуск №303 (5976), 


\section{1 декабря 2012 г.}

Говоря в целом, существующую литературу вопроса давно уже не окинуть взглядом, что вполне закономерно в движении исследовательской мысли. Да и технический прогресс её тоже очень подталкивал и подталкивает... Тем более что компьютеризация обиходного уровня в нашей стране по ряду политических причин, мягко говоря, запаздывала...

Нашему современнику, мало-мальски знакомому с историей Западно-Европейской гуманитарной мысли середины второго тысячелетия новой эры, да и с русской историей века так с 17-го тоже, в этом контексте, а лучше, наверное, - в контенте, как сейчас принято в более знакомом звучании того же самого, нелишне вспомнить другое. Лет пятьсот назад, когда в Европе появилось книгопечатание, а потом - столетие-другое спустя, - когда тиражная книга стала доступна пошире, многим казалось, что книгопечатание породило возможность индивидуализации знания. Читай - учись, умней! Вся историко-цивилизационная человеческая мудрость от античности до новых дней - доступна, перед тобой! Сиди в библиотеке или дома, постигай! Казалось, школы и университеты - не нужны!

Однако приходится констатировать, что жизнь быстро опрокинула эти умонастроения. Главным же, наоборот, стало противоположное: книгопечатание множило школы и университеты! И это, безусловно, аксиома! Давайте согласимся с тем, что такие исторические факты и умозрительные созвучия наталкивают на исторические параллели. Это значит, что гуманитарное содержание здесь - то же, ну а отличие - лишь в техническом воплощении образовательной практики, преобразуемой безостановочным техническим прогрессом в его стремительном движении... Вроде всё так просто: хватай Жар-птицу за хвост! Учись онлайн, сидя на печке и любуясь собой, таким умнейшим, на цветном дисплее! Такое даже прежним советским студентам-заочникам и присниться не могло!

Приходится констатировать и то, что жизнь всегда многообразнее любых прожектов и умозрений. Всесторонняя образовательная практика последнего года на всех уровнях нашей образовательной системы - это хорошо подтвердила, буквально опрокинув многие имевшиеся представления и исследовательские модели, и построения. И обучающие, и обучаемые, вплотную столкнувшись с реальностью, быстро поняли, что и то, и другое оказалось слишком преждевременным и по техническим реалиям, и по предметно-методическим возможностям.

Сегодня проблематика дистанционного обучения это одна из ключевых тем публицистики. И это понят- но: дистант ныне - универсальная тема, напрямую или опосредованно волнующая и беспокоящая едва ли не каждого, иначе говоря - притча не только во языцех, но и в умах современников всех возрастов. Ведь объемы образовательной сферы всесторонни и невероятно велики. Поэтому в условиях самоизоляции при пандемии коронавируса дистант и коснулся всех: и отцов, и детей... И весь преподавательский корпус - от учителей начальных классов школы до профессуры и академиков.

При этом всем вдруг и сразу стало предельно ясно, что получение образования вне учебных классов и аудиторий, т.е. вне корпоративности и когнитивности, малоэффективно. Следует подчеркнуть, что понятие «корпоративность» в буквальном переводе с латинского - это «объединенный», а значит - принадлежащий к группе, связанной общими целями и устремлениями, интересами и взглядами, в том числе и направленными на перспективу.

Когнитивность же, как известно, - это способность охватывать весь объем информации, который мы приобретаем благодаря обучению, а также практике и опыту, получаемым и формируемым в своей корпоративной среде. Собственный опыт подсказывает, что в нашем случае - это преподаватель, аудитория, учебная группа, курс, факультет. Когнитивность - это способность воспринимать и обрабатывать данные и информацию, поступающие к нам через восприятие и убеждения, чтобы превратить их в знание, опыт и практику.

Эта способность охватывает единство различных процессов - обучение, внимание, память, речь, рассуждение, принятие решений, которые являются частью интеллектуального развития и опыта. На наш взгляд, реализация этого единства в условиях самоизоляции и дистанцированности весьма проблематична. В подтверждение нашего взгляда приведём очень компетентное мнение, принадлежащее Сергею Рощину, проректору Высшей школы экономики: «Дистанционное обучение не может заменить живого человеческого общения, обмена энергетикой, прямого контакта и наставничества» [9]. Вопрос в том, как «организовать дистант так, чтобы этот контакт был максимален».

Универсальность этой проблемы быстро сформировала широкую площадку для всесторонней дискуссионности именно на уровне не академизма, а публицистики. Всем вдруг стало понятно, что реальная практика быстро и во многом опрокинула академическое умозрение, опережавшее технические возможности дистанта, то есть дистанционного обучения, и не учитывавшее сполна человеческий фактор, то есть реальный уровень компьютерной грамотности. И это неудивительно: романтизм, теория и практика обычно плохо ладят друг с другом. Поэтому с самого начала самоизоляции споры 
по поводу дистанционного обучения, всколыхнувшие общество, и не утихают. И это сфера публицистики.

Говоря же о технических возможностях дистанта, невольно приходит в голову парафраз: «Славно было на планшете, да как плохи наши сети, а ведь в них висеть...» На любой платформе, заметим! Поэтому, судя по всему, в ближайшие годы нас ждёт программа компьютерной сетефикации всей страны. Такой общегосударственный опыт в нашем 20 веке был: вспомним проводную радиофикацию всей страны в 1920-30-е годы, когда железные репродукторы появились на всех улицах и площадях, а чёрную «тарелку» трансляционной радиосети притащили в каждый дом, квартиру и избу... Целеполагание тогда было, правда, совсем иным: идеология заставляла. Зато сейчас технические возможности у страны несравненно другие! Да и от прогресса - не спрячешься! Пандемия актуализировала дистант, дистанционное обучение скорректировало важную техническую задачу. С учётом охвата, плотности, ёмкости и скорости сетей, конечно...

Важнейшим вопросом наших дней стала реализации федерального проекта «Цифровая образовательная среда», в рамках которого планируется масштабная цифровизация отрасли. В том числе создание автоматических рабочих мест учителя или преподавателя, обеспечение школ скоростным интернетом, организация внутренних локальных сетей для обеспечения одновременной работы нескольких десятков учителей, ведение электронного документооборота, электронных классных журналов, электронных дневников, автоматического контроля успеваемости и многое другое. С полным основанием можно утверждать, что эти же задачи во многом стоят и перед высшей школой.

«Четверть российских педагогов отмечает, что их навыков и знаний недостаточно для перехода на дистанционное обучение. «Чаще о нехватке навыков и знаний говорят учителя школ (27\% против 19\% среди преподавателей вузов)», - уточняют эксперты. В то же время оценка собственной методической готовности к ведению занятий в дистанционном формате среди школьных учителей и преподавателей вузов примерно одинакова: большинство оценивают ее удовлетворительно - 55\%. Преподаватели вузов также часто жалуются на высокую нагрузку и нехватку времени в связи с переходом на дистанционное обучение: школьные учителя - на отсутствие компьютеров и доступа в интернет у учащихся. Большинство педагогов (74\%) отметили рост рабочей нагрузки в связи с переходом к дистанционному обучению, а более четверти (26\%) пожаловались на плохую организацию перехода от традиционного обучения в онлайн. При этом 60\% охарактеризовали переход как удовлетворительный и только $14 \%$ назвали его хорошо организованным» [5], - констатировала в апреле 2020 года в большой аналитической статье столичной «Неза- висимой газеты» Ольга Соловьёва.

Человеческий фактор, однако, вызывает оптимизм. Компьютерная грамотность - настойчивое требование времени. И она неуклонно растёт и ширится, в том числе и в старших возрастных группах, во всех социальных слоях. Говоря о высшей школе, отметим следующее: понятно, что все студенты хакерами не станут. Понятно, что дистанционное обучение и не требует этого уровня. Скорость современных планшетов и ноутбуков позволяет и сегодня использовать их куда эффективнее. Только вот общедоступные компьютерные сети и действующие образовательные дистанционные платформы должны успешно выдерживать даже форс-мажорные нагрузки...

Понятно ведь и то, что и после пандемии, а значит - в очень близком будущем, элементы дистанционного обучения останутся: будет использоваться смешанный формат, который позволит использовать все плюсы онлайна и очного преподавания» [9]. Однако, основываясь на общем взгляде преподавателей и студентов, известном автору этих строк изнутри, хочется быть уверенным в том, что упомянутый выше «смешанный формат» объективно предполагает абсолютное преобладание очного преподавания, то есть офлайна. Вообще говоря, как видится сегодня, категория «смешанный формат преподавания» не может не настораживать, потому что объективно он рождает соблазн какой-то «оптимизации» учебного процесса, тем более - в высшей школе, чего очень бы не хотелось по причинам, отмеченными нами выше.

Теория, как известно, проверяется практикой. Это вековечная аксиома! Практика преподавания, базирующаяся на технических возможностях электронного дистанта, то есть, подчеркнём, дистанционного обучения, сегодня, как уже отмечалось, способна опрокинуть многие умозрительные теоретизирования, опережавшие технические реалии. Давайте согласимся с тем, что образование не может быть виртуальным или, хуже того, ирреальным.

Нельзя упустить из виду и философию вопроса, а «философия исходит из интуиции целого, поэтому все части её должны представлять систему, исключающую возможность противоречий» $(11,11)$. И эта формула Эрнеста Леопольдовича Радлова, видного русского философа Серебряного века, доныне незыблема и именно универсальна.

Основные проблемы дистанционного образования названы. В начале этой статьи нами уже было отмечено мнение основателя Международного Ломоносовского клуба Владимира Скрипниченко, что российской системе образования по ряду причин понадобится несколько лет для организации полноценного дистанционного обучения. «Во-первых, на сегодняшний день у нас отсут- 
ствует полноценный единый ресурс для дистанционки» [7]. Во-вторых, «остается открытым вопрос развития у школьников когнитивных навыков - ученик изолирован от класса, коллективных компетенций, от живого общения с педагогами и сверстниками и личного примера». Абсолютно то же применимо и в высшей школе, но в более значимых и ёмких аспектах. Самая же большая задача, которую еще предстоит решить, состоит в том, что «вовлеченность на живом уроке на порядки превышает онлайн» [7]. То же и в высшей школе: «Главная проблема дистанта - отсутствие мотивации у студентов» [9]. Отметим, что это мнение эксперта особенно значимо! В-третьих, «пока остается открытым вопрос, как достичь целей без потери в качестве образования в моменте, особенно когда пока еще нет так называемых best practices, потому что с аналогичными проблемами с дистанционным обучением сталкиваются во всем мире» [7]. И это значит, что пандемия коронавируса застала врасплох не только систему образования в России...

Нельзя, наконец, не обозначить и четвёртую проблему, имеющую прикладное, но очень существенное содержание. «Интернет и хорошие компьютеры находятся в распоряжении далеко не всех студентов, некоторым студентам дома не хватает комнаты или даже стола для занятий. <...> Да и само понятие дистанционного обучения оказалось весьма неопределенным. Оказалось, что все понимают его по-своему. При этом многие [сегодня, наверное, все. - Р.Т.] сходятся на том, что необходим прямой видео- и аудиоконтакт студента и преподавателя. Однако в деталях начинаются расхождения. Часть преподавателей искренне полагают, что студент читает методичку и решает задачки по составленной заранее программе, а преподаватель в эфире лишь консультирует. Кто-то, кто потрудился раньше, записал и выложил в интернете видеозаписи своих лекций, сделал на них ссылку на своей персональной страничке преподавателя. А кто-то считает, что онлайн - это обычные лекции и семинары, но только при помощи компьютеров, заменяющих всем аудиторию с доской. Последний способ, наиболее интересный и привлекательный для студентов, оказался невероятно энергоёмким. В результате лекция или семинар длятся, как обычно, два академических часа, а вот подготовка онлайн-презентации и составление последующего отчёта требуют целого дня с частью ночи. В результате продвинутый онлайн-преподаватель стал проводить за компьютером не менее 12 часов в день. Вредная для здоровья вещь - онлайн-преподавание!» [6], - завершил оригинальным выводом свои рассуждения доктор физико-математических наук, преподаватель МГУ Дмитрий Миллионщиков, подводя итоги весеннего семестра 2020 года. Полностью разделяя высказанную точку зрения, могу с уверенностью предположить, что с ней охотно согласится абсолютное большинство преподавателей, причём независимо от уровня собственной компьютерной грамотности или даже мастерства.
На взгляд преподавателя, «самый сложный вопрос дистанционного обучения звучит так: «Как проводить онлайн экзамен?» Это основной вопрос, который сейчас мучает всё преподавательское сообщество. Как обеспечить объективный контроль за экзаменом? В интернете мы видим огромное количество специальных сайтов под типовым названием «экзамен.ру». Они предлагают помощь в написании онлайн-контрольных и экзаменационных работ за очень небольшие деньги. Как проверить, что присланная на образовательный портал письменная работа студента действительно честно написана именно этим студентом? Первые же опыты экзаменов без видеоконтроля показали большие статистические выбросы отличных и хороших оценок при нулевом количестве двоек и почти нулевом количестве троек. Но и видеоконтроль не спасает полностью. Вовсе не случайно много раз переносился в стране экзамен ЕГЭ. При этом не надо забывать, что в отличие от ЕГЭ экзаменуемый студент находится у себя дома, а не в специально оборудованном помещении. Со вздохом многие из нас согласились на такие псевдоэкзамены, уговаривая себя, что «это лишь на один раз, это временная мера» [6], - отмечал летом 2020 года Дмитрий Миллионщиков. Готова поддержать каждое слово автора!

Приходится констатировать, что обозначенное понятие «временный» может иметь очень широкие хронологические параметры. Вот подтверждение из школьной практики: «ЕГЭ по-прежнему нужен для получения школьного аттестата. То, что эту норму отменили в 2020 году из-за пандемии, было продиктовано исключительными обстоятельствами. Но отменять обязательный ЕГЭ в 2021 году пока не планируется, так же как и переводить экзамен в дистанционный формат. - Не думаю, что существующие технологии сегодня позволяют нам пойти на такой шаг, - уверен руководитель Рособрнадзора Анзор Мусаев. - Провести ЕГЭ дистанционно сейчас невозможно» [8]. Последняя фраза в приведённой цитации особенно интересна тем, что объективно она универсальная для любого экзамена вообще. Ведь, как уже цитировалось выше, «первые же опыты экзаменов без видеоконтроля показали большие статистические выбросы отличных и хороших оценок при нулевом количестве двоек и почти нулевом количестве троек» [6].

Сегодня уже трудно поверить в то, что совсем недавно - даже ещё в самом начале 2020 года - перспективы дистанционного обучения представлялись вполне реальными и безоблачными. И это имело под собой почву. «В этой связи стоит отметить статью Корниенко С.А. «Электронное обучение как средство реализации образовательной программы», опубликованную в сборнике V Международной научной конференции «Педагогика: традиции и инновации». Приведем выдержку из публикации: «Под дистанционным обучением (distance learning) стали понимать такой процесс обучения, при 
котором используются технологии, не предполагающие непосредственного присутствия преподавателя - в первую очередь, информационно-коммуникационные технологии. В англоязычной образовательной литературе часто используется термин «ореn and distance learning» - «открытое и дистанционное обучение», подчеркивающий тот факт, что по сравнению с традиционным обучением дистанционное открыто для более широкой аудитории. Открытое обучение не предполагает вступительных экзаменов и доступно любому желающему; более того, оно может быть «неформальным» (nonformal, informal learning), т.е. не завершатся получением соответствующих документов об образовании. Именно в это время и получило развитие электронное обучение, которое на этом этапе развития служило «технически улучшенной формой дистанционного обучения» $[4,20]$.

В этом цитируемом тексте 2014 года всё очень конкретно, точно, безукоризненно и весьма перспективно! К тому же автор показательно демонстрирует неплохое знакомство с зарубежными источниками информации. И это тоже точно! Нелишне предположить, что, в силу своей конкретики и точности, такой обоснованный взгляд может иметь очень неплохую перспективу в будущем. Значит, в нормальных грядущих условиях, конечно. Нынешние же тотальные форс-мажорные обстоятельства, связанные с пандемией, к сожалению, потребовали иных реальных действий, и тоже тотальных, заметно поубавивших оптимизма в сфере дистанта на всех уровнях образовательной системы страны. Во всяком случае - на ближайшую перспективу... И это лишь подтверждает непредсказуемое многообразие жизни, в том числе и академической, имеющей свойство корректировать планы, ожидания и, казалось бы, прогнозируемые надежды. Приходится невольно констатировать, что в социальной и гуманитарной сферах это обычно наиболее заметно любому современному обществу, более чем ощутимо для него, а потому наиболее чувствительно.

В самоизоляции пандемических реалий 2020 года, имея в виду дистант, то есть, повторюсь в который раз, дистанционное обучение, и преподавая в высшей школе, пришлось, к очень большому образовательному сожалению, каждодневно - из месяца в месяц, а потом и дольше, - почувствовать ещё и его реальные пределы. Иначе говоря - весьма ограниченные возможности нынешней технической компьютерной сферы республик, областей, городов и весей, где, как оптимистично представлялось всем нам прежде, и вопросов-то вроде не возникало насчёт будущей дистанционки, хотя бы школьной... Ну на общий неширокий взгляд, хотя бы... Понятно ведь каждому было, что от неё - от этой школьной и вузовской дистанционки - в ближней перспективе в стране по разным там поводам никуда не деться... Что уж скрывать: давайте, коллеги, не постесняемся сказать об этом в открытую... Время и техническое развитие объективно подталкивали к этому. Но кому же могло прийти в голову одномоментное тотальное введение дистанционного обучения на всех уровнях и в нашей стране, и в мире?

Прежде, до грянувшей в 2020-м пандемии коронавируса и самоизоляции, думалось и виделось всё совсем иначе... Вот умственные наблюдение и созерцание, вот умозрение, а вот и синтез того и другого, как учила и учит философия. Уже и до концепции добраться вроде можно... Понятно ведь, что какая-то соответствующая диалектика вопроса и широкое исключение противоречивости всегда будут рядом... Иначе говоря, зачем вообще и нужно умозрение...

Академическая препарация проблемы, того или иного вопроса обычно основательно иллюстрирует или доказывает в статьях и заметках, мнениях и диссертациях свою точность и правоту. В нашей академической практике с этим никто и спорить не станет. Соответствующая родная академическая школа у нас очень мощная! И это замечательно! Вот отличный образец того, о чём сказано чуть выше.

«Дистанционная форма процессов образования, зародившаяся еще в XVI-XVII вв. [где, простите? - Р.T.], получила свое широкое распространение в конце $X X$ века [в каких объёмах и границах, простите? - Р.Т.]. В современной литературе имеется достаточное количество работ, анализирующих проблемы управления, развития, содержания и результативности данной формы образования. На причинах широкого распространения дистанционной формы образования в современной России акцентировал внимание Л.Я. Аверьянов, который считал, что «... одной из самых негативных и социально болезненных диспропорций является неравенство возможности получения образования. Индивид может пренебречь этими возможностями - по нерадивости, предпочтению других сфер деятельности, или по каким-либо принципиальным соображениям. Это дело выбора. Но выбор ему должно предоставить общество, претендующее называться цивилизованным. <...> Образование сегодня выполняет не только функцию поддержания социального престижа, но и, по сути, функцию социализации, ибо войти в мир знаков-символов возможно только с определенной образовательной ступени».

Дистанционное обучение в Российской Федерации начинает приобретать официальный статус с начала 1990-х гг., а в 1995 году была принята «Концепция создания и развития единой системы дистанционного образования в России», созданная для повышения доступности и качества учебных программ и обусловленная «высокой социальной значимостью дистанционного образования, сформировавшихся потребностей в нем и наличия у России необходимого кадрового педагогиче- 
ского, научно-технического и научно-методического потенциалов и финансовых возможностей».

В настоящее время российское дистанционное высшее образование регламентируется Федеральным законом №273-Ф3 «Об образовании в Российской Федерации» от 29 декабря 2012 г., Постановлением Правительства Российской Федерации №966 от 28 октября 2013 г. «О лицензировании образовательной деятельности», приказом Рособрнадзора №1953 от 05.09.2011 г. «Об утверждении лицензионных нормативов к наличию у лицензиата учебной, учебно-методической литературы и иных библиотечно-информационных ресурсов и средств обеспечения образовательного процесса, по реализуемым в соответствии с лицензией на осуществление образовательной деятельности образовательным программам высшего профессионального образования» [2].

Здесь вроде всё ясно: названные нормативные основы известны всем нашим преподавателям любого уровня, как и понятны тоже. В цитируемом тексте всё динамично и словесно очень конкретно. Кроме «знаковсимволов», и зацепиться взглядом не за что... Да и то потому лишь, что многоступенчатая система образования нашей страны - это вовсе не «знаки-символы»...

Дальше в этом же тексте 2015 года - в цветных, ярких сегментных диаграммах - сказано и всё другое: необходимость дистанционного образования (ДО) шесть лет назад, в 2015 году, считали нужной 92\% опрошенных квалифицированных преподавателей вуза, а в будущем, естественно, - оставшиеся 8 процентов. Влияние ДО на конкурентность вуза - 87,3\%. Главное, правда, было впереди и оказалось неожиданным: среди тех же квалифицированных преподавателей положительно отнеслись к ДО лишь 45\%, а ещё 30\% из тех же квалифицированных не сочли ДО перспективным... 25 же процентов оставшихся, кстати - тоже квалифицированных, оказались нейтральными в своих оценках [2]. Понятно, что «квалифицированные преподаватели» - это те, кто квалифицированно ладит с компьютерными техникой и практикой, с современными коммуникационными средствами. На первый взгляд, непонятно другое - соотношение цифр, представленных в процентных отношениях. Именно: если ДО на примере вуза сочли нужным 92\% опрошенных, то почему положительно отнеслись к нему лишь $45 \%$, а остальные 55\%, что же, думали иначе?

На наш взгляд, здесь всё логично и правильно. Противостоять техническому прогрессу и развитию информационных технологий - нелепо и смешно в любом возрасте и с любым уровнем собственной преподавательской соответствующей «квалифицированности». Каждый из преподавателей подтвердит необходимость ДО как «столбовой дороженьки» в отдалённой перспективе. И вот они - названные 92 процента! Может, впрочем, быть и больше. Не приходится сомневаться, что среди них и указанные выше 55 процентов опрошенных «квалифицированных преподавателей», не столь оптимистичных в широких практических перспективах ДО обозримого времени.

Могу уверенно сказать, что если бы автору этих строк пришлось столкнуться с вопросом: как вы оцениваете перспективы ДО, ответ был бы однозначным: в дальней перспективе - не знаю, в ближней - положительно, но лишь в прикладном, вспомогательном, узко адресованном и конкретно направленном значениях. На наш взгляд, диалектика вопроса как процесс его развития в нынешних реалиях очень показательна тем, что электронно-революционная ломка не в интересах любой из сторон всей образовательной системы и её процесса.

Практические аспекты тотального дистанционного образования в форс-мажорных обстоятельствах пандемии предельно точно сформулировали существо нашего взгляда и оценку ближней перспективы ДО. Смею думать, в обеих сферам образовательного процесса - и обучающих, и обучающихся. И объём подобной оценки может быть очень велик, потому что «всем пришлось столкнуться с неожиданными трудностями в связи с введением режима самоизоляции. Система образования оказалась на первой линии фронта с большим количеством обучаемых и обучающих: около 1,5 миллиона школьных учителей и преподавателей вузов, а также 16 миллионов школьников и 7 миллионов студентов» [5].

Анализируя проблемы обстоятельств, вызванные пандемией, автор статьи «Половина российских преподавателей не готовы к удаленному обучению: Высшее и среднее образование вошло в кризисный режим трансформации» Ольга Соловьёва отмечает: «Сейчас даже вскрываются более глубокие проблемы, считает руководитель исследовательской группы Центра трансформации образования Московской школы управления «Сколково» Дара Мельник. «Например, программ развития преподавательского мастерства в «обычное» время не было, а сейчас преподавателям не хватает методик и инструментов, чтобы делать свою работу хорошо. Вузы недостаточно цифровизированы, и образовательный процесс переходит в онлайн раньше, чем система управления», - говорит она. Нет понимания того, как должна в новых условиях определяться преподавательская нагрузка, добавляет эксперт. «В любом случае нельзя во время шторма строить новый корабль. Нужно фиксировать вскрывающиеся проблемы и использовать те технические средства, к которым все привыкли», - считает Мельник [5]. И эту точку зрения просто нельзя не поддержать.

Именно поэтому «цифровые профессора» [термин С. 
Рощина. - Р.Т.], начитанные «в электронке» полные курсы лекций и практические задания, онлайн-семинарии в диалоге «преподаватель $\leftrightarrow$ студент» и коллоквиумы по той же схеме - вполне возможная практика вспомогательного дистанционного обучения в реалиях современности. Вне форс-мажора, в обычное время. Экзамены, конечно же, - наяву, вживую, не виртуально! Однако подчеркнём: - это именно узко адресованная практика, едва ли не индивидуализированная или персонифицированная в конкретном назначении.

В поддержку нашего мнения можно привести и социальный аспект ДО в условиях самоизоляции, вызванной форс-мажорными обстоятельствами, связанными с пандемией. «Переход на дистанционное обучение вызывает обеспокоенность в российской Счётной палате и в связи с угрозой дополнительного социального расслоения. «На практике онлайн-обучение приносит непропорционально большую пользу учащимся с изначально более выгодным положением (при расслоении по линии богатые-бедные; проживающие в городе - на селе; с хорошими показателями успеваемости - с плохими показателями). Это означает, что для большинства школьников и студентов дистанционное образование принесет меньше пользы», - замечают в Счетной палате [5]. Столь серьёзное мнение не вызывает возражений, но больше обеспокоенность...

В тексте наших заметок ранее уже отмечалось, что всеобщее дистанционное обучение, вызванное условиями самоизоляции, поубавило оптимизма исследователей в его вопросах, проблемах и перспективах. Академических статей и заметок в библиографии 2020 года, можно сказать, почти не видно. Движение жизни своим многообразием, в том числе и непредсказуемыми реалиями, внесло существенные коррективы в умонастроения и умозрение. В этих обстоятельствах, как обычно и бывает, на первый план, как уже указывалось, вышла публицистика. Нельзя не признать, что её доводы и аналитика по кругу рассматриваемых нами вопросов, в реалиях пандемии особенно актуальны и доказательны, как нельзя не признать и то, что они находят широкий живой отклик и их интересно использовать в свою поддержку.

Не могу не признать, что реальную практику массового дистанционного обучения и его ближних перспектив сегодня, в наших условиях, можно рассматривать лишь в концепции ограниченного оптимизма. Как нельзя не признать и того, что совсем недавно, до введения всеобщего дистанционного обучения в условиях самоизоляции, многое казалось иначе... Вот уж, действительно, уникальное свидетельство того, что теория проверяется практикой. В нашем случае - огромной, протяжённой, тотальной практикой... Дистанционное же обучение в условиях самоизоляции предстало именно макротестом для всей образовательной системы страны, её готовности работать в условиях дистанционного обучения. Результаты этого теста оказались сегодня малоутешительными...

Следует подчеркнуть, что российские исследователи в течение предыдущих десятилетий серьёзно занимались вопросами и проблемами дистанционного обучения и образования во всех их аспектах - от предпосылок и терминологии - до актуальных задач.

«Российская система высшего образования обладает фундаментальной научной базой, позволяющей готовить всесторонне развитого выпускника, однако наступившая информационная эра и глобализация в образовании требуют ее модернизации, применения новых подходов к организации деятельности высшей школы. Характер развития института образования должен быть максимально инновационным, что в значительной степени обуславливается тем, что он остается базовым инструментом для трансляции знаний в различные сферы человеческой деятельности. Сочетание мощных и доступных информационных технологий, компьютеризация населения привели к формированию дистанционного образования», - отмечала ещё в 2015 году А.А. Савастьина, подчёркивавшая активную научную дискуссионность вокруг дистанционного образования [3, 178]. Поэтому специальное внимание она уделила и терминологии вопроса.

«В действующем Федеральном законе от 29.12.2012 №273-Ф3 «Об образовании в Российской Федерации» присутствует определение «электронное обучение», которое не в полной мере является синонимом дистанционного обучения. Для дистанционного обучения принципиально не важно, каким образом образовательные материалы будут доставляться от вуза к студенту. Электронное обучение подразумевает доставку всего образовательного материала в электронном виде с использованием компьютерных сетей» [3, 178]. При этом, полемизируя с рядом исследователей по определению содержания понятия «дистанционное обучение», А.А. Савастьина не соглашается с мнением В.Г. Домрачеева, понимающего дистанционное обучение как «новую ступень заочного обучения, на которой обеспечивается применение информационных технологий, основанных на использовании персональных компьютеров, видеотехники, аудио-техники, космической и оптоволоконной техники», или с другим мнением: «Е.С. Полат полагает, что «дистанционное обучение - это организованный по определенным темам, учебным дисциплинам учебный процесс, предусматривающий активный обмен информацией между учащимися и преподавателем, а также между самими учащимися, и использующий в максимальной степени современные средства новых информационных технологий (аудиовизуальные средства, персональные компьютеры, средства телекоммуника- 
ций)» $[3,179]$. На взгляд А.А. Савастьиной, «приведенные определения понятия «дистанционное обучение» не раскрывают его сущность в полной мере, страдают односторонностью подхода. Наиболее полное определение категории «дистанционное обучение» определяют исследователи Московского государственного университета экономики, статистики и информатики [в 2015 г. МЭСИ вошёл в структуру РЭУ им. Г.В. Плеханова. - Р.Т.], утверждая, что дистанционное обучение - это «целенаправленный процесс интерактивного взаимодействия обучающих и со средствами обучения, инвариантный (индифферентный) к их расположению в пространстве и времени, который реализуется в специфической дидактической системе» $[3,179]$.

Признавая сложность восприятия приведённой дефиниции МЭСИ, с мнением А.А. Савастьиной всё-таки нельзя не согласиться. Любая научная или прикладная дисциплина оперирует своей точной терминологией, формулами и определениями. Попробуйте разобраться с отличиями и тонкостями содержания таких ключевых понятий, как «дистанционное обучение» и «дистанционное образование», «дистанционное обучение», «электронное обучение», «цифровое обучение». Приходится констатировать, что сегодня именно широкими слоями специалистов системы образования они воспринимаются просто как обычный синонимический ряд новейшего и оптимального термина «дистант», порождённого, наверное, дистанционным обучением периода самоизоляции в условиях пандемии коронавируса. Вот интересная деталь к содержанию этого вопроса. Уже в начале одной из очень серьёзных статей её «авторы обращают внимание на то, что в статье рассматривается и анализируется именно дистанционное обучение, а не дистанционное образование. Дистанционное образование не рассматривается, потому что, несмотря на все его преимущества, оно пока у нас абсолютно неэффективно, а зачастую просто вредно, не способствует раскрытию личностного потенциала» [1, 12-13]. По мере знания существа этих отличий, так сказать изнутри, готова всячески поддержать авторов приведённой нами цитации.
В завершение наших заметок нельзя не сказать и об очень важном. В своей программной статье «Проблемы развития дистанционного обучения в России», опубликованной ещё в 2013 году, доктор экономических наук, профессор Е.Р. Орлова и кандидат экономических наук, старший научный сотрудник Института системного анализа РАН Е.Н. Кошкина, рассматривая наиболее существенные проблемы, присущие развитию дистанционного обучения, «справедливости ради» отметили, что, по их мнению, можно выделить следующие проблемы, присущие нынешнему [на 2013 год. - Р.Т.] состоянию дистанционных технологий в образовательной сфере России:

1) проблема внедрения дистанционных технологий в обучение; 2) проблема качества дистанционного обучения; 3) проблема финансирования; 4) проблема информирования российских студентов и слушателей о наличии качественных дистанционных курсов (отсутствие сайта в Интернете); 5) отсутствие методик для эффективной реализации дистанционного обучения; 6) проблема организации систем дистанционного обучения; 7) проблема отсутствия системы обучения преподавателей использованию информационно-коммуникационных технологий (ИКТ)» $[1,12]$.

С того времени минуло восемь лет. Немалый срок! Однако широкая проблематика вопроса, предельно точно обозначенная авторами цитируемой статьи, не потеряла актуальности ни по одной из семи названных позиций. Более того, реалии дистанционного обучения в условиях самоизоляции студентов, школьников и преподавателей всех уровней системы образования страны предельно актуализировали эту проблематику. Значит, не менее актуальным остаётся и общий вопрос, тоже звучавший в прежние годы: не преждевременно ли пока говорить всерьёз о дистанционном обучении? Имея в виду, в особой частности, и электронные коммуникационные или компьютерные сети - их надёжность, мощности, скорости и плотность охвата, с чего, собственно, мы и начинали свои заметки. Как и прежде, общий вывод о преждевременности масштабного дистанта, похоже, не только идёт в ногу со временем, но и опережает его.

\section{ЛИТЕРАТУРА}

1. Орлова Е.Р., Кошкина Е.Н. Проблемы развития дистанционного обучения в России.//Приоритеты России. - 2013. - №23.

2. Ребышева Л.В., Васильченко Е.В. Проблемы дистанционного образования на современном этапе развития.//ЭнЖ «Современные проблемы науки и образования». - 2015. - №2 (часть 2); URL: http://www.science-education.ru/ru/article/view?id=22704.

3. Савастьина А.А. Проблемы внедрения дистанционного обучения в образовательный процесс.//Вестник Челябинского государственного университета. 2015. - №19 (374). Философия. Социология. Культурология. Вып. 37. С.178-181.

4. Пробин П.С. Проблемы формирования образовательных коммуникаций в высшей школе посредством дистанционных платформ обучения.// 0бразовательные ресурсы и технологии. - 2017. - №4 (21). С.20-23.

5. Соловьева Ольга. Половина российских преподавателей не готовы к удаленному обучению: Высшее и среднее образование вошло в кризисный режим трансформации.//Независимая газета. - 2020, 7 апреля. On-Line версия. 
6. Миллионщиков Дмитрий; Кузьминов Ярослав. К онлайну оказались готовы не все: Как карантин выявил основные проблемы высшего образования в России. - Источник: FORBES.RU 2020, 17 июня. https://vogazeta.ru/articles/tags/5870

7. Названы основные проблемы дистанционного обучения в России: Владимир Скрипниченко.//MA REGNUM, 2020, 9 oктября. https://regnum.ru/news/ society/3086318.html.

8. К Колесникова Ксения. Плюс-минус балл: Что ждёт школьников на ЕГЭ-2021.//Российская газета. - 2020, 20 октября.

9. Рощин Сергей, проректор Высшей школы экономики. Дистант в вузе: как не потерять в качестве./Российская газета. - 2020, 28 декабря.

10. Федеральный закон от 29 декабря 2012 г. №273-Ф3 «06 образовании в Российской Федерации». // Российская газета. - Федеральный выпуск №303 (5976). 31 декабря 2012 г.

11. Радлов Э.Л. Введение в философию. - Петербург, 1919. - 55 с.

(c) Татаринцева Регина Игоревна (regina_tatarinceva@mail.ru).

Журнал «Современная наука: актуальные проблемы теории и практики»

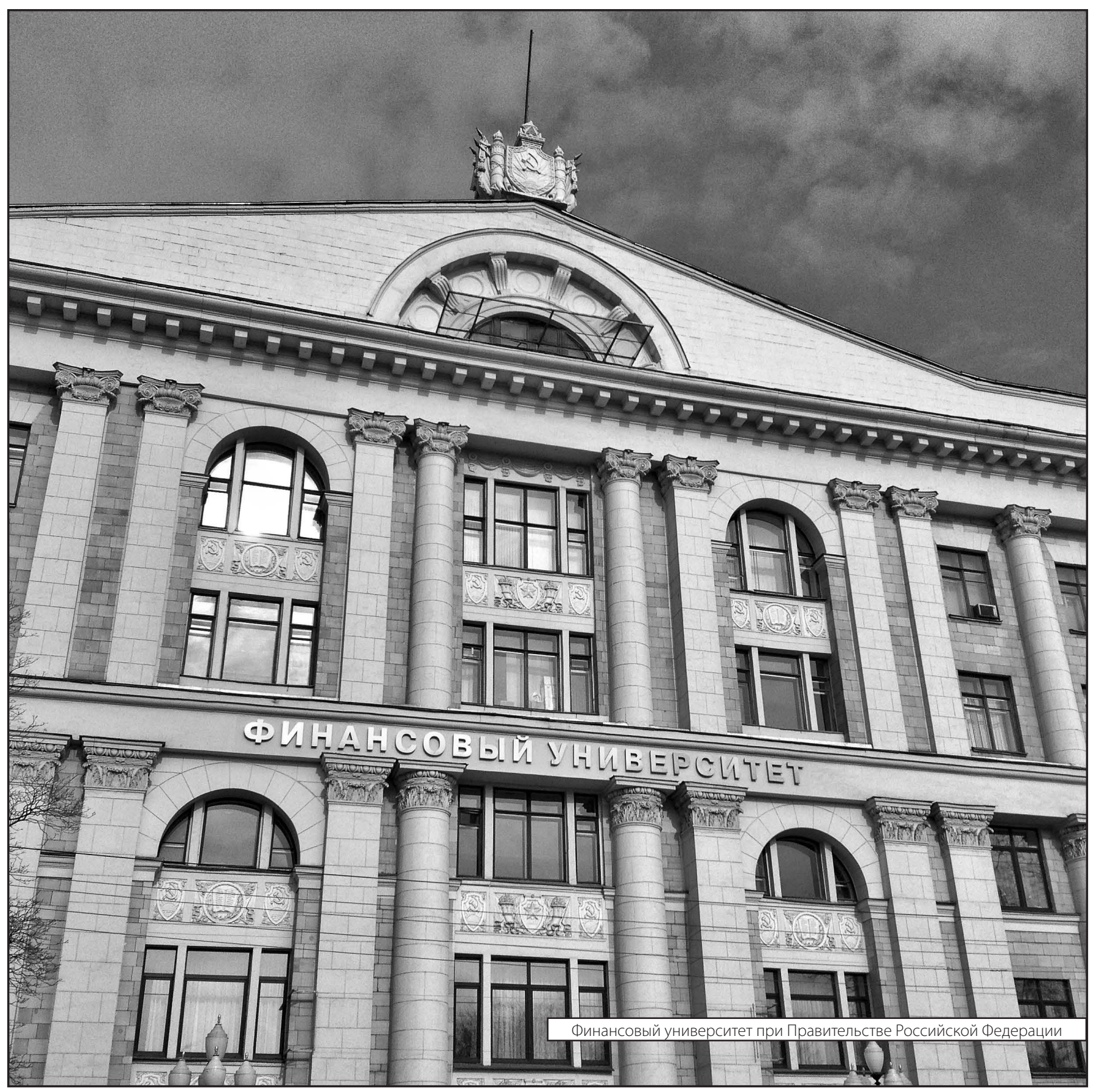

